\title{
Awareness and Follow up of Breast Cancer in a Young Female
}

\section{Rikki Singal ${ }^{1 *}$, Deepak Narang ${ }^{2}$, Rohit Dang ${ }^{1}$, Karan Bakshish ${ }^{1}$ and Prakhar Garg ${ }^{1}$}

${ }^{1}$ Department of Surgery, Maharishi Markandeshwer Institute of Medical Sciences and Research, Mullana, Distt- Ambala, Pin Code-13303, Haryana, India ${ }^{2}$ Department of Anaestheisa, Maharishi Markandeshwer Institute of Medical Sciences and Research, Mullana, Distt- Ambala, Pin Code-13303, Haryana, India

\begin{abstract}
Although uncommon, breast cancer in young women is worthy of special attention due to the unique and complex issues that are raised. A 26-year young female reported with a breast lump on right side. On fine needle aspiration, it was diagnosed as breast carcinoma which is rarely seen in young cases. It is widely believed that breast carcinoma in young women is characterized by a relatively unfavourable prognosis and unusual pathological features. Despite the data available in the specialist literature, it is not yet clear whether breast cancers arising in young women are biologically different from those found in older women. Most of the published studies on this issue have focused on relatively large cohorts of premenopausal patients.
\end{abstract}

Keywords: Diagnosis; Quality of life; Treatment; Premenopausal; Awareness

\section{Introduction}

Breast cancer in women aged younger than 35 years old comprises approximately $3 \%$ of Japanese breast cancer patients. Interestingly, the estimated breast cancer incidence in young women under 40 years of age is approximately 25 per 100,000 women be it in Japan or the USA or the European Union, whereas breast cancer incidence in all ages is higher in Western than in Asian countries [1]. Younger women with breast cancer are known to have worse prognoses than their older counterparts [2]. In this comprehensive evaluation of breast cancer arising in young women, an analysis of age-specific differences in prognosis, clinicopathological variables, gene expression patterns, and oncogenic signaling pathways, thus combining traditional prognostic variables with phenotypes and providing insight into the unique biology of breast cancer [3].

Breast cancer risk factors can be broadly classified as nonmodifiable risks, including age, race/ethnicity, genetics/family history, and age at menarche and modifiable risk factors, including diet, alcohol consumption, overweight, smoking and physical. Both low-fat and high-fibre diets may be weakly protective against breast cancer [4]. Interestingly, breast cancer risk factors, clinical outcomes, and tumor biology are somewhat different in the subgroup of women below 40, suggesting that breast cancer in young women represents a distinct entity $[5,6]$. The present study was aimed at finding any biological differences by comparing the clinicopathological features of 50 young breast cancer patients under 40 with those of 50 postmenopausal women aged 60 years or older.

\section{Case Report}

A 26-year-young female complained of a swelling in the right breast since 7 months. The lump was small in size and had increased to the present size with enlargement of the breast. She was having pain in the breast and loss of appetite for which she took medicine from the local doctor. She refused to go for surgical treatment in early stage of presentation. She came to us with increase in size of the breast and lump. There was no family history of breast disease.

On examination, the lump was present in the upper, outer quadrant on side of the right breast. The right sided nipple was inverted and the breast was enlarged as compared to the left breast. Vessels were seen overlying of the breast skin without any skin changes. The lump was $12 \times 8 \mathrm{~cm}$ in size, hard in consistency (Figure 1). It was not fixed to the underlying structures. There were three lymph nodes felt in the right axilla, mobile in nature and non-tender. On fine needle aspiration cytology, diagnosis was made as breast carcinoma. Modified radical mastectomy with primary closure of the skin was done. The gross cut section of the specimen revealed a large tumor of about size $12 \times 10 \mathrm{~cm}$, whitish in color (Figure 2). On histopathology, diagnosis came as infiltrating ductal carcinoma and ten lymph nodes were seen. On follow-up, she was put on an adjuvant chemotherapy course of 5-fluorouracil, cyclophosphamide, and methotrexate, and discharged on Tamoxifen $20 \mathrm{mg}$ once a day. Patient is in still four years follow-up, without any recurrence and is asymptomatic.

\section{Discussion}

Breast cancer is one of the most prevalent cancers in females, The definition of a 'young woman' in the field of breast oncology varies, with most articles referring to women under either age 35 or 40 years as 'young'. Population-based studies have identified young age as an independent predictor of adverse breast cancer-specific outcome [3]. Breast cancer incidence increases with age, with the vast majority of women diagnosed after the age of 40 years. $5 \%-7 \%$ of breast cancer cases occur in women under 40 years of age. Breast cancer in the young has gained increased attention with an attempt to improve diagnosis and prognosis. Young patients tend to have different epidemiology, presenting with later stages and more aggressive phenotypes [6,7]. The incidence of a positive family history in the current series was similar to the general population with breast carcinoma, suggesting that the relatives of very young women with breast carcinoma do not require especially intensive screening. Walker et al. [8] reported a broadly similar incidence of positive family history in women aged 35-44 years compared to those under 35, but Chan et al. [9] reported a family history in $29 \%$ of women aged $<35$ with breast cancer. Of the

*Corresponding author: Dr. Rikki Singal, Department of Surgery, Maharish Markandeshwer Institute of Medical Sciences and Research, Mullana, Distt-Ambala, Pin Code-13303, Haryana, India, Tel: 09996184795; Fax No-01731304550; E-mail: singalsurgery@yahoo.com

Received January 27, 2015; Accepted February 12, 2015; Published February 16, 2015

Citation: Singal R, Narang D, Dang R, Bakshish K, Garg P (2015) Awareness and Follow up of Breast Cancer in a Young Female. J Health Med Informat 6: 181 doi:10.4172/2157-7420.1000181

Copyright: ( 2015 Singal R, et al. This is an open-access article distributed under the terms of the Creative Commons Attribution License, which permits unrestricted use, distribution, and reproduction in any medium, provided the original author and source are credited. 


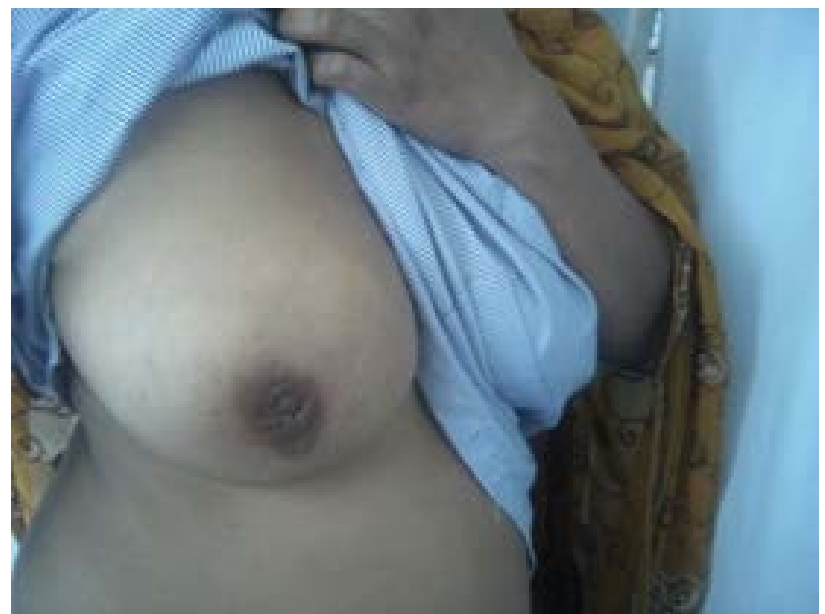

Figure 1: Gross Appearance of the Enlarged Breast and showing Inverted Nipple.

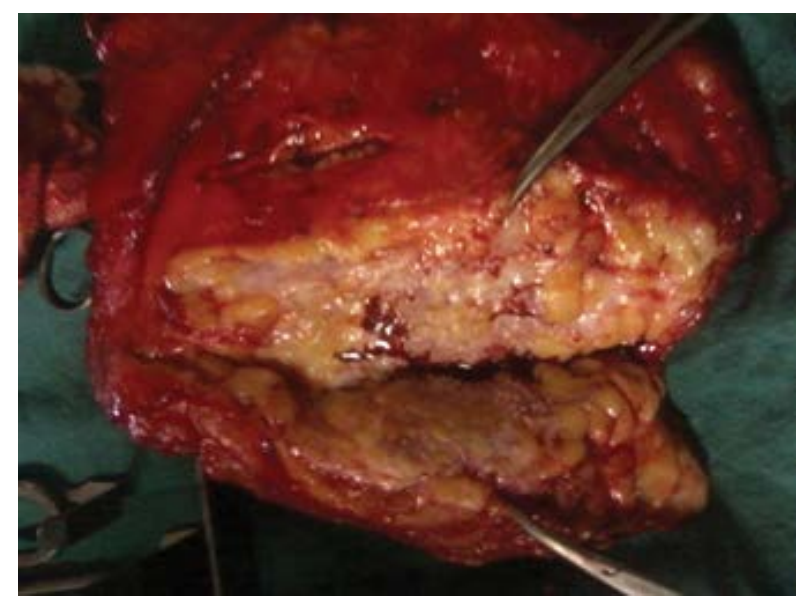

Figure 2: Gross cut section of the Breast Tumor.

two cases with a positive family history, both had high-grade invasive breast carcinomas, but neither was of a medullary subtype typical of BRCA mutations.

It has been suggested that the mean primary tumor size at presentation is greater in women $\leq 35$ years but in the current series and others, this was not the case. Another author found no significant difference between very young and young women, or any difference between all young women taken together $(\leq 35$ years) and a large cohort of older women (36-65 years). Conversely, there was a steady increase in mean tumor size with increasing age within the group of older women $(P=0.0108)$ [10]. Biological evaluation revealed negativity for CERB-2, p53 and Bcl-2, but a high proliferation value (Ki 67: 47 and $85 \%$ ), higher in the younger patient in consideration of the aggressiveness of this kind of lesions [11]. In the general breast cancer population, the recurrence rate and the disease-free survival rates are similar between women receiving BCT or mastectomy [7]. The worse prognosis may be because greater numbers of younger women have tumors with poor clinicopathological features, i.e., more advanced TNM stage at presentation and more hormone receptor negative tumors as demonstrated in previous studies [12].

Given the limitations of mammography in dense breast tissue, ultrasound and breast-specific magnetic resonance imaging (MRI) are frequently used in the diagnostic setting. Although screening is not recommended for women at average risk prior to age 40 , it is important to note that annual breast MRI is currently recommended for screening of unaffected women starting at age 30 if they have a lifetime breast cancer risk at or exceeding 20\%-25\%. Similar to ultrasound, MRI has a high sensitivity, but low specificity for breast cancer, which may lead to unnecessary biopsies. However, MRI has still been shown to be more sensitive than mammogram in the dense breast population [13]. Azim HA concluded that proliferation-related prognostic gene signatures could aid in treatment decision-making independent of age. This may be particularly clinically relevant for the young given the potential longterm side effects of adjuvant systemic chemotherapy. Furthermore, young age adds extra biological complexity, which is independent of differences in breast cancer subtype distribution. Although these results require further validation, either experimentally or in other clinical data sets, we suggest that separate therapeutic approaches may need to be specifically designed to improve outcomes for breast cancer arising in young women [2]

Treatment should be based on the pathological features of the tumor rather than the age of the patient, but very young women have excessive risk of local recurrence and dying, as compared to their middle-aged counterparts, even if diagnosed early and receiving an intense treatment [14]. In particular, surgical choices impact emotional status and quality of life. Mastectomy appeared to have a greater effect on quality of life [15]. In the overall breast cancer population, patients with BCT reported better body image, more physical functioning, and higher sexual activity after 5 years [16].

\section{Conclusion}

The care of young women with breast cancer has become a more recent focus with improvements in diagnosis, treatment, and survivorship. Given the differences in epidemiology and management options, as well as the unique issues surrounding fertility, sexuality, and pregnancy, the multidisciplinary approach to treatment for these women frequently may also incorporate other areas of expertise.

\section{References}

1. Shimizu C (2014) Breast cancer in young women: it's biological and clinica uniqueness and needs of comprehensive care. Breast Cancer 21: 641-642.

2. Azim HA, Michiels S, Bedard PL, Singhal SK, Criscitiello C, et al (2012) Elucidating prognosis and biology of breast cancer arising in young women using gene expression profiling. Clin Cancer Res 18: 1341-1351.

3. Anders CK, Hsu DS, Broadwater G, Acharya CR, Foekens JA, et al. (2008) Young age at diagnosis correlates with worse prognosis and defines a subse of breast cancers with sharedpatterns of gene expression. J Clin Oncol 26: 3324-3330.

4. Peltzer K, Pengpid S (2014) Awareness of Breast Cancer Risk among Female University Students from 24 Low, Middle Income and Emerging Economy Countries. Asian Pac J Cancer Prev 15: 7875-7878.

5. Gabriel CA, Domchek SM (2010) Breast cancer in young women. Breas Cancer Res 12: 212

6. Anders CK, Johnson R, Litton J, Phillips M, Bleyer A (2009) Breast cancer before age 40 years. Semin Oncol 36: 237-249.

7. Reyna C, Lee MC (2014) Breast cancer in young women: special considerations in multidisciplinary care. J Multidiscip Health 7: 419-429.

8. Walker RA, Lees E, Webb MB, Dearing SJ (1996) Breast carcinomas occurring in young women (<35 years) are different. $\mathrm{Br} J$ Cancer 74: 1796-1800.

9. Chan A, Pintilie M, Vallis K, Girourd C, Goss P (2000) Breast cancer in women $\leq 35$ years: review of 1002 cases from a single institution. Ann Oncol 11: 12551262. 
Citation: Singal R, Narang D, Dang R, Bakshish K, Garg P (2015) Awareness and Follow up of Breast Cancer in a Young Female. J Health Med Informat 6: 181. doi:10.4172/2157-7420.1000181

Page 3 of 3

10. Kothari AS, Beechey-Newman N, D'Arrigo C, Hanby AM, Ryder K,et al.(2002) Breast carcinoma in women age 25 years or less. Cancer 94: 606-614.

11. Batori M, Ruggieri M, Chatelou E, Straniero A, Mariotta G, et al. (2006) Breas cancer in young women: case report and a review. European Review for Medical and Pharmacological Sciences 10: 51-52.

12. Kataoka A, Tokunaga E, Masuda N, Shien T, Kawabata K, et al. (2013) Clinicopathological features of young patients $(<35$ years of age) with breast cancer in a Japanese Breast Cancer Society supported study. Breast Cancer 21: $643-650$.
13. Pediconi F, Catalano C, Roselli A, Dominelli V, Cagioli S, et al (2009) The challenge of imaging dense breast parenchyma: is magnetic resonance mammography the technique of choice? A comparative study with $\mathrm{x}$-ray mammography and whole-breast ultrasound. Invest Radiol 44: 412-421.

14. Singal R, Gupta $S$ (2012) Operable breast cancer in a young female: A rare presentation. Clin Cancer Investig J 1: 109-110.

15. Lee MC, Bhati RS, von Rottenthaler EE, Reagan AM, Karver SB, et al. (2013) Therapy choices and quality of life in young breast cancer survivors: a shortterm follow-up. Am J Surg 206: 625-631.

16. Arndt V, Stegmaier C, Ziegler H, Brenner $\mathrm{H}$ (2008) Quality of life over 5 years in women with breast cancer after breast-conserving therapy versus mastectomy: a population-based study. J Cancer Res Clin Oncol 134: 1311-1318. 